\title{
Characterisation and optimisation of a sample preparation method for the detection and quantification of atmospherically relevant carbonyl compounds in aqueous medium
}

\author{
M. Rodigast, A. Mutzel, Y. Iinuma, S. Haferkorn, and H. Herrmann \\ Leibniz-Institute for Tropospheric Research (TROPOS), Atmospheric Chemistry Department (ACD), Permoserstr. 15, \\ 04318 Leipzig, Germany
}

Correspondence to: H. Herrmann (herrmann@tropos.de)

Received: 4 December 2014 - Published in Atmos. Meas. Tech. Discuss.: 23 January 2015

Revised: 19 May 2015 - Accepted: 20 May 2015 - Published: 8 June 2015

\begin{abstract}
Carbonyl compounds are ubiquitous in the atmosphere and either emitted primarily from anthropogenic and biogenic sources or they are produced secondarily from the oxidation of volatile organic compounds. Despite a number of studies about the quantification of carbonyl compounds a comprehensive description of optimised methods is scarce for the quantification of atmospherically relevant carbonyl compounds. The method optimisation was conducted for seven atmospherically relevant carbonyl compounds including acrolein, benzaldehyde, glyoxal, methyl glyoxal, methacrolein, methyl vinyl ketone and 2,3-butanedione. $O$ (2,3,4,5,6-pentafluorobenzyl)hydroxylamine hydrochloride (PFBHA) was used as derivatisation reagent and the formed oximes were detected by gas chromatography/mass spectrometry (GC/MS). With the present method quantification can be carried out for each carbonyl compound originating from fog, cloud and rain or sampled from the gas- and particle phase in water. Detection limits between 0.01 and $0.17 \mu \mathrm{mol} \mathrm{L}^{-1}$ were found, depending on carbonyl compounds. Furthermore, best results were found for the derivatisation with a PFBHA concentration of $0.43 \mathrm{mg} \mathrm{mL}^{-1}$ for $24 \mathrm{~h}$ followed by a subsequent extraction with dichloromethane for $30 \mathrm{~min}$ at $\mathrm{pH}=1$. The optimised method was evaluated in the present study by the $\mathrm{OH}$ radical initiated oxidation of 3-methylbutanone in the aqueous phase. Methyl glyoxal and 2,3-butanedione were found to be oxidation products in the samples with a yield of $2 \%$ for methyl glyoxal and $14 \%$ for 2,3-butanedione after a reaction time of $5 \mathrm{~h}$.
\end{abstract}

\section{Introduction}

Carbonyl compounds are ubiquitous in the atmosphere and they play an important role in the atmospheric gas- and particle phase chemistry (Grosjean, 1982). They are directly emitted from both biogenic and anthropogenic sources (Carlier et al., 1986) and they can be formed secondarily during the oxidation of volatile organic compounds (VOCs) (Hallquist et al., 2009). According to the literature, carbonyl compounds represent 79 and $89 \%$ of the alkane and alkene oxidation products in the presence of $\mathrm{NO}_{x}$, respectively (Calvert and Madronich, 1987). According to their Henry constants carbonyl compounds partition into the aqueous phase and due to their high solubility in water they can undergo multiphase reactions (Ravishankara, 1997; Schaefer et al., 2012). Reactions in the aqueous phase can be divided into radical reactions (Herrmann et al., 1999) and non-radical reactions such as aldol condensation (Loeffler et al., 2006), leading to various multifunctional products.

Numerous methods exist to detect and quantify carbonyl compounds in atmospheric samples. These methods can be categorised into spectroscopy-based techniques such as differential optical absorption spectroscopy (DOAS, Platt et al., 1979), Fourier transform infrared spectroscopy (FT-IR, Tuazon et al., 1978) and mass spectrometry (MS) based techniques such as online proton transfer reaction mass spectrometry (PTR-MS), offline gas chromatography coupled to mass spectrometry (GC/MS) and liquid chromatography coupled to mass spectrometry (LC/MS). For the GC/MS and LC/MS techniques carbonyl compounds often require a derivatisation step prior 
to analysis. Among several derivatisation reagents 2,4dinitrophenylhydrazine (DNPH, Lowe et al., 1980) and $o$ (2,3,4,5,6-pentafluorobenzyl)hydroxylamine hydrochloride (PFBHA) are most commonly used for the analysis of atmospheric carbonyl compounds.

In the present study, thorough characterisation of a PFBHA-based derivatisation method was performed and an improvement was made to achieve a more efficient and optimal quantification of atmospheric relevant carbonyl compounds in aqueous samples originating from various sources (aqueous aerosol extracts, fog, cloud and rain samples). Furthermore, such samples can also be formed from gas phase sampling into aqueous solutions by mist chambers (Seaman et al., 2006) and impinger samples (Lelacheur et al., 1993) or by partitioning sampling techniques such as C-GIS (condensation growth and impaction system; Sierau et al., 2003), MARGA (Monitor for Aerosols and Gases in Air; ten Brink et al., 2009) and PILS (particle into liquid sampler; Sorooshian et al., 2006). The carbonyl compounds investigated in the present study were acrolein, methacrolein, methyl vinyl ketone, benzaldehyde, glyoxal, methyl glyoxal and 2,3-butanedione. These compounds were chosen because of their atmospheric relevance. Acrolein is emitted from incomplete combustion (Seaman et al., 2009) and formed during the oxidation of VOCs (1,3-dienes) with a mixing ratio between 0.13 and $7 \mathrm{ppb}$ in ambient atmosphere (Altshuller, 1983). This compound has an adverse health effect leading to asthma and other chronic lung diseases (Leikauf, 2002). Methacrolein and methyl vinyl ketone are the major firstgeneration oxidation products of isoprene (Kroll et al., 2006). They are suggested to be precursor compounds for glyoxal and methyl glyoxal in the atmospheric aqueous phase. In addition to isoprene oxidation glyoxal and methyl glyoxal are produced in the oxidation of a variety of VOCs (Fu et al., 2008). Due to their high water solubility they partition into the atmospheric aqueous phase, acting as precursor compounds for the formation of secondary organic aerosol (Ervens and Volkamer, 2010). Benzaldehyde can be formed in oxidation of aromatic VOCs such toluene and mixing ratios in the range of higher ppb levels in polluted regions are reported (Jang and Kamens, 2001). The oxidation of aromatic VOCs also forms 2,3-butanedione (Atkinson and Aschmann, 1994; Schütze and Herrmann, 2004). Since 2,3-butanedione was found in the atmospheric aqueous phase it was used as a compound for the method development as well.

\section{Experimental}

\subsection{Sample preparation}

$150 \mu \mathrm{L}$ of the internal standard (cyclohexanone-2,2,6,6-d4, $0.1 \mu \mathrm{mol} \mathrm{L}-1$ ) was added to $3 \mathrm{~mL}$ of the aqueous standard solution. The solution contains the following seven authentic standard compounds: acrolein, benzaldehyde, glyoxal, methyl glyoxal, methacrolein, methyl vinyl ketone and 2,3butanedione $\left(8 \mu \mathrm{mol} \mathrm{L}^{-1}\right.$ each). To optimise the PFBHA derivatisation method the influence of the extraction and derivatisation time, the PFBHA amount, the $\mathrm{pH}$ value and the extraction solvent was investigated and the measurements were repeated for three times. According to the optimal reaction parameters identified, $5 \mathrm{mg}$ PFBHA was solved in $1 \mathrm{~mL}$ water and $300 \mu \mathrm{L}$ of the solution was added to the samples reaching a PFBHA concentration of $0.43 \mathrm{mg} \mathrm{mL}^{-1}$. Afterwards the samples are allowed to rest for $24 \mathrm{~h}$ at room temperature. Then, the sample was acidified with hydrochloric acid $(37 \%)$ to $\mathrm{pH}=1$, mixed with $250 \mu \mathrm{L}$ dichloromethane and shaken with an orbital shaker for $30 \mathrm{~min}(1500 \mathrm{rpm}$, revolutions per minute). Afterwards $1 \mu \mathrm{L}$ of the organic phase was injected into GC. For further information about the chemicals and standards see Supplement Sect. S1.

\subsection{Batch reactor experiment}

Experiments were conducted in a $300 \mathrm{~mL}$ batch reactor containing a $0.1 \mathrm{mmol} \mathrm{L}^{-1}$ solution of 3-methylbutanone and a $10 \mathrm{mmol} \mathrm{L}^{-1}$ hydrogen peroxide solution. The photolysis of hydrogen peroxide with a xenon-mercury lamp $(500 \mathrm{~W}$; LOT-Oriel GmbH \& Co. KG, Darmstadt, Germany) was used as $\mathrm{OH}$ radical source. The reaction mixture was continuously stirred over the course of the experiment and $3 \mathrm{~mL}$ samples were taken after each hour. The samples were treated as described in Sect. 2.1.

\subsection{GC/MS analysis}

The samples were analysed using a 6890 Series GC System (Agilent Technologies, Santa Clara, USA) coupled with an electron ionisation quadrupole mass spectrometer (Agilent 5973 Network mass selective detector, Santa Clara, USA). For separation a HP-5MS UI column (Agilent J \& W GC columns, $30 \mathrm{~m} \times 0.25 \mathrm{~mm} \times 0.25 \mu \mathrm{m}$ ) was used. The temperature programme was as follows: $50^{\circ} \mathrm{C}$ isothermal for $2 \mathrm{~min}$ and elevated to $230^{\circ} \mathrm{C}$ with $10^{\circ} \mathrm{C} \mathrm{min}^{-1}$. The temperature of $230^{\circ} \mathrm{C}$ was held for $1 \mathrm{~min}$. The temperature gradient ended with $320^{\circ} \mathrm{C}$ which was held constant for $10 \mathrm{~min}$. The inlet was operated in the splitless mode at a temperature of $250^{\circ} \mathrm{C}$.

\section{Results}

Studies that optimised a method for the quantification of carbonyl compounds using PFBHA derivatisation are summarised in Table 1. Even though numerous studies exist optimising the derivatisation with PFBHA, only those methods are included in Table 1 which (i) derivatise carbonyl compounds in aqueous phase (derivatisation on solid phase, cartridges or on a chip are not compared: Cullere et al., 2004; Nawrocki et al., 1996; Pang et al., 2013), (ii) optimise one of the investigated reaction parameters that are also investigated within the present study and (iii) use the same extrac- 
tion techniques as in the present study (solid phase micro extraction or extraction on fibre are not included, e.g. Cancho et al., 2002). Additionally, in Table S1 (Supplement Sect. S2.1) the application of the PFBHA derivatisation method is summarised.

To improve commonly used PFBHA methods, a mixture of seven standard compounds (acrolein, methacrolein, methyl vinyl ketone, glyoxal, methyl glyoxal, benzaldehyde, 2,3-butanedione) mixed with an internal standard (cyclohexanone-2,2,6,6-d4) was used. The internal standard was used as reference for the GC/MS method or in the case of quantification to correct the peak areas for losses that might occur between sampling and detection. Derivatisation parameters were optimised using a standard stock solution of $8 \mu \mathrm{mol} \mathrm{L}^{-1}$.

In general, the derivatisation of a carbonyl compound leads to the formation of $(\mathrm{E})$ and $(\mathrm{Z})$ isomers resulting in two peaks per compound in the chromatogram (Glaze et al., 1989). As the ratios of the peak areas for (E) and (Z) isomers were found to stay constant, one peak per compound was considered for the method optimisation. Optimised parameters for the derivatisation procedure include the extraction solvent, extraction and derivatisation time, the amount of PFBHA and $\mathrm{pH}$ value before and after derivatisation (Table 2).

\subsection{Extraction solvent}

Hexane, dichloromethane, toluene and chlorobenzene are reported in the literature as suitable extraction solvents (Spaulding and Charles, 2002; Ye et al., 2011; Glaze et al., 1989; Strassnig et al., 2000). Within the present study these reported extraction solvents (hexane, dichloromethane, toluene) were investigated as well, in addition to isooctane and chloroform. Figure 1 illustrates the influence of the extraction solvent on the amount of detected carbonyl compounds. Surprisingly, from the comparison dichloromethane turned out to be the most effective extraction solvent, which was among numerous of studies only described by Spaulding and Charles (2002). This is in contrast to former studies where hexane was commonly used as extraction solvent (EPA method 556, 1998; Glaze et al., 1989; Lelacheur et al., 1993; Seaman et al., 2006; Serrano et al., 2013). In the present study hexane resulted in lower peak areas of the carbonyl compounds due to less effective extraction. In turn this underestimation leads to a higher detection limit compared to other extraction reagents (Table 3). Notably, toluene is recommended in the literature as extraction solvent (Strassnig et al., 2000). This can be confirmed at least for the extraction of benzaldehyde. The better extraction of benzaldehyde with toluene is likely due to the aromatic character of both toluene and benzaldehyde.

Detection limits were determined for the present study in the single ion mode (SIM) based on a signal-to-noise ratio $(S / N)$ of $\geq 3$ and compared to those reported by Glaze et

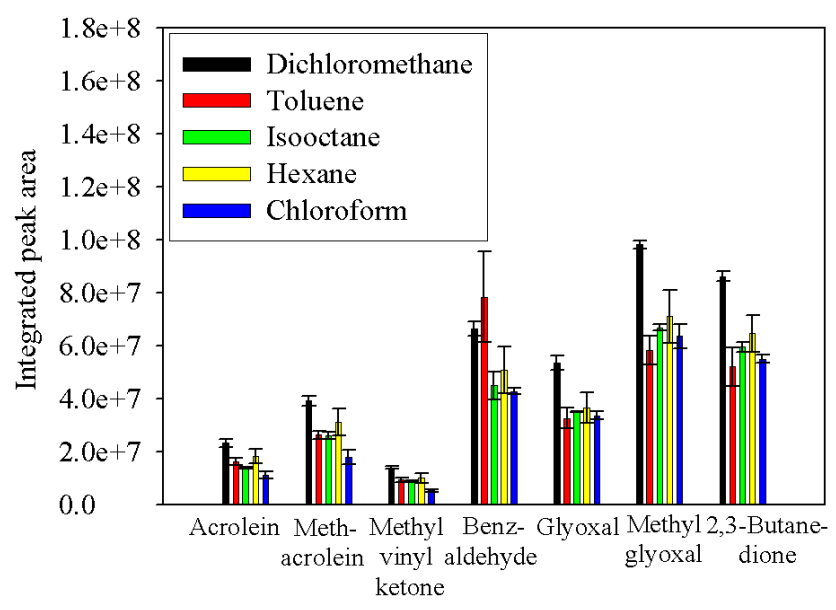

Figure 1. Influence of the extraction solvent dichloromethane (black), toluene (red), isooctane (green), hexane (yellow) and chloroform (blue) on the integrated peak areas of the standard compounds acrolein, methacrolein, methyl vinyl ketone, benzaldehyde, glyoxal, methyl glyoxal and 2,3-butanedione.

al. (1989) - note that $5.6 \mathrm{~mL}$ of the sample was extracted with $1 \mathrm{~mL}$ hexane resulting in a preconcentration factor of $\approx 6$ (Glaze et al., 1989). In the present study a preconcentration factor of $\approx 12$ was reached. In the case of acrolein this preconcentration results in a detection limit of $0.17 \mu \mathrm{mol} \mathrm{L}^{-1}$ which is improved by a factor of $\approx 2$ compared to Glaze et al. (1989). The detection limit of other investigated compounds showed an improvement by about a factor of 10 . The detection limits were as follows: $0.01 \pm 0.0003 \mu \mathrm{mol} \mathrm{L}^{-1}$ for benzaldehyde, $0.01 \pm 0.0004 \mu \mathrm{mol} \mathrm{L}^{-1}$ for methyl glyoxal and $0.01 \pm 0.0006 \mu \mathrm{mol} \mathrm{L}^{-1}$ for glyoxal (for more details see Sect. S2.2 and Table 3). Based on the low standard deviations, it can be stated that the extraction with dichloromethane results in a high reproducibility.

Due to the high reproducibility and low detection limits, dichloromethane was chosen as extraction solvent.

\subsection{Extraction time}

In addition to the extraction solvent, it was found that the extraction time had a significant influence on the quantity of the extracted amount of derivatised carbonyl compound (Fig. S1; Supplement Sect. S2.3). It was found that the integrated peak areas increase with an increasing extraction time. An extraction time less than $15 \mathrm{~min}$ was not sufficiently long enough to extract the target analytes completely.

This is different from previous findings with $2 \mathrm{~min}$ (Ye et al., 2011) and 3 min extraction time (EPA method 556, 1998). However, the data on the influence of the extraction time is scarce and no further method development was found in the literature examining this issue. Furthermore, most studies in the past used very short extraction times (e.g. Glaze et al., 1989; Lelacheur et al., 1993; Serrano et al., 2013). These 
Table 1. Studies reporting the optimisation of a PFBHA method and fulfilling the selection criteria: (i) derivatise carbonyl compounds in the aqueous phase (derivatisation on solid phase, cartridges or on a chip are not compared: Cullere et al. (2004); Nawrocki et al. (1996); Pang et al. (2013), (ii) optimise one of the reaction parameters investigated within this study and (iii) use the same extraction techniques as in the present study (solid phase micro extraction or extraction on fibre are not included, e.g. Cancho et al., 2002). The optimised method parameters are given in bold and the parameters matching with the present study are underlined.

\begin{tabular}{|c|c|c|c|c|}
\hline PFBHA [mg mL $\left.{ }^{-1}\right]$ & Derivatisation time & Extraction solvent & Extraction time [min] & Reference \\
\hline 0.1 & $40 \mathrm{~min}, 24 \mathrm{~h}$ for ketones ${ }^{*}$ & Ethyl acetate & - & Kobayashi et al. (1980) \\
\hline 0.1 & $2 \mathrm{~h}$ (longer for ketones)* & Hexane & 0.5 & Glaze et al. (1989) \\
\hline$>10$-fold excess & $24 \mathbf{h} *$ & Hexane, Methyltert-butyl ether & 1 & Lelacheur et al. (1993) \\
\hline 0.8 & $20 \mathrm{~s}(900 \mathrm{~W})$ & Toluene & - & Strassnig et al. (2000) \\
\hline 0.5 & $24 \mathrm{~h}^{*}$ & Dichloromethane & - & Spaulding and Charles (2002) \\
\hline$\overline{0.06}$ & $\overline{4 h}\left(60^{\circ} \mathrm{C}\right)$ & $\overline{-}$ & - & Sugaya et al. (2004) \\
\hline 0.2 & 24-96 h* & Hexane & - & Seaman et al. (2006) \\
\hline 0.06 & $2 \mathbf{h}^{*}$ & - & - & Hudson et al. (2007) \\
\hline- & $4 h^{*}$ & - & - & Takeuchi et al. (2007) \\
\hline 0.75 & $10 \min ^{*}$ & - & - & Saison et al. (2009) \\
\hline 0.05 & $<10 \min ^{*}$ & Chlorobenzene & 2 & Ye et al. (2011) \\
\hline 0.5 & $1 \min \left(60^{\circ} \mathrm{C}\right)$ & Hexane & 1 & Serrano et al. (2013) \\
\hline 0.75 & $2 \mathrm{~h}\left(35^{\circ} \mathrm{C}\right)$ & Hexane & 3 & EPA method 556 (1998) \\
\hline 0.4 & $24 h$ & Dichloromethane & 30 & This work \\
\hline
\end{tabular}

* derivatisation at room temperature.

Table 2. Overview about the investigated parameters.

\begin{tabular}{|c|c|}
\hline Parameter & Range \\
\hline \multirow[t]{5}{*}{ Extraction solvent } & Dichloromethane \\
\hline & Toluene \\
\hline & Hexane \\
\hline & Isooctane \\
\hline & Chloroform \\
\hline Extraction time & $5,15, \mathbf{3 0}, 60 \mathrm{~min}$ \\
\hline Derivatisation time & $0.5,1,2,6, \mathbf{2 4}, 48 \mathrm{~h}$ \\
\hline Added amount of PFBHA & $0.09,0.22, \mathbf{0 . 4 3}, 0.86,1.72 \mathrm{mg} \mathrm{mL}^{-1}$ \\
\hline pH value (Derivatisation) & $\mathrm{pH}=1, \mathbf{3}, 5,7$ \\
\hline pH value (Extraction) & $\mathrm{pH}=\mathbf{1}, 3,5,7$ \\
\hline
\end{tabular}

shorter extraction times likely cause significantly lower peak areas of the oximes and therefore higher detection limits (Table 3). Furthermore, the incomplete extraction caused by the short extraction times might lead to a decreasing reproducibility.

To ensure a complete extraction of the analytes, the extraction time was extended to $30 \mathrm{~min}$, and the extraction procedure was repeated 3 times. After the first extraction the amount of detected oxime was negligibly small $(\approx 2 \%$, Table S2; Supplement Sect. S2.3) indicating an almost complete extraction within 30 min, e.g. methyl vinyl ketone, benzaldehyde and methyl glyoxal showed an extraction efficiency of $98 \% \pm 2 \%$ after the first extraction. Based on this, an extraction time of $30 \mathrm{~min}$ can be recommended. Because hexane is the commonly used extraction solvent, the influence of the extraction time was also investigated for hexane. The extraction with hexane showed the same result regard- ing the extraction time as was found for dichloromethane. Thus the extraction was complete after an extraction time of $30 \mathrm{~min}$. To ensure the comparability of hexane (commonly used) and dichloromethane, extraction factors were determined (see Supplement Sect. S2.3).

\subsection{Derivatisation time}

The influence of the derivatisation time was evaluated using a duration ranging from 0.5 to $48 \mathrm{~h}$ (Fig. S3, Supplement Sect. S2.4). For all the investigated carbonyl compounds it was found that the reaction was almost completed after $24 \mathrm{~h}$. Thus, it can be recommend to use a derivatisation time of $24 \mathrm{~h}$, that is in good agreement to the findings by Lelacheur et al. (1993) and Kobayashi et al. (1980). Nevertheless, optimised derivatisation times can be found ranging from $20 \mathrm{~s}$ to $96 \mathrm{~h}$ for the carbonyl compounds investigated in the literature studies (EPA method 556, 1998; Glaze et al., 1989; Hudson et al., 2007; Kobayashi et al., 1980; Lelacheur et al., 1993; Saison et al., 2009; Seaman et al., 2006; Serrano et al., 2013; Strassnig et al., 2000; Sugaya et al., 2004; Takeuchi et al., 2007). Among various compounds investigated in the literature the atmospheric relevant compounds formaldehyde, acetaldehyde, butanal, methyl ethyl ketone and methyl butyl ketone were used (Glaze et al., 1989). In the study by Glaze et al. (1989) an optimal derivatisation time of $2 \mathrm{~h}$ for aldehydes was found but much longer derivatisation times were identified for ketones. The difference between that study and the results obtained within the present study might be caused by the carbonyl compounds used for the optimisation. Only small, saturated aldehydes like acetaldehyde were used during the investigations of Glaze and co-workers 
Table 3. Detection limits of the carbonyl compounds determined in the present study with GC/MS (SIM) and in the literature.

\begin{tabular}{|c|c|c|c|c|c|c|}
\hline \multirow[t]{2}{*}{ Carbonyl compound } & \multicolumn{4}{|c|}{ Detection limits $\left[\mu \mathrm{mol} \mathrm{L}^{-1}\right]$ in the literature studies } & \multicolumn{2}{|l|}{ This work $\mathrm{S} / \mathrm{N} \geq 3, n=3$} \\
\hline & Glaze et al. (1989) & Seaman et al. (2006)* & Serrano et al. (2013) & EPA method 556 (1998) & Detection limit $\pm \mathrm{SD}\left[\mu \mathrm{mol}^{-1}\right]$ & $\operatorname{RSD}[\%]$ \\
\hline Acrolein & 0.3 & $8.6 \times 10^{-3}-2.5 \times 10^{-2}$ & - & - & $0.17 \pm 0.03$ & \pm 19 \\
\hline Methacrolein & - & $4.0 \times 10^{-2}-1.9 \times 10^{-2}$ & - & - & $0.02 \pm 0.003$ & \pm 16 \\
\hline Methyl vinyl ketone & - & $2.2 \times 10^{-2}-2.9 \times 10^{-2}$ & - & - & $0.03 \pm 0.003$ & \pm 10 \\
\hline Benzaldehyde & 0.1 & $7.5 \times 10^{-3}-1.7 \times 10^{-2}$ & $0.1 \times 10^{-3}$ & 0.003 & $0.01 \pm 0.0003$ & \pm 3 \\
\hline Glyoxal & 0.1 & $3.5 \times 10^{-2}-1.5 \times 10^{-1}$ & $0.01 \times 10^{-3}$ & 0.01 & $0.01 \pm 0.0006$ & \pm 5 \\
\hline Methyl glyoxal & 0.1 & $1.6 \times 10^{-2}-2.1 \times 10^{-2}$ & $0.01 \times 10^{-3}$ & 0.01 & $0.01 \pm 0.0004$ & \pm 4 \\
\hline 2,3-Butanedione & - & - & - & - & $0.01 \pm 0.0008$ & \pm 8 \\
\hline
\end{tabular}

whereas much larger carbonyl compounds were used in the present study. It can be expected that the molecule size has also an influence on the optimal derivatisation time and this might explain the observed differences.

Nevertheless, a shorter derivatisation time of $2-4 \mathrm{~h}$ has also been reported in literature where, however, only acetone and formaldehyde (Hudson et al., 2007; Takeuchi et al., 2007) were considered. Contrary, longer derivatisation times of 24 to $96 \mathrm{~h}$ were observed as an optimal result by Seaman et al. (2006). They reported that glyoxal and methyl glyoxal needed longer derivatisation times due to their two carbonyl groups. Furthermore, the carbonyl compounds were sampled and derivatised in a sodium bisulfite solution. After the carbonyl-bisulfite adduct was formed, hydrogen peroxide was added to destroy the formed adduct and to yield carbonyl compounds which were directly derivatised with PFBHA. These steps were conducted simultaneously which might cause the longer derivatisation times.

Certain few studies optimising derivatisation with PFBHA cannot be considered for a comparison because they were conducted under higher temperatures (EPA method 556, 1998; Serrano et al., 2013; Sugaya et al., 2004) or they used microwave-assisted derivatisation (Strassnig et al., 2000).

\subsection{Influence of the PFBHA concentration}

To investigate the influence of the amount of derivatisation reagent, PFBHA concentration in the sample solution was varied from 0.09 to $1.72 \mathrm{mg} \mathrm{mL}^{-1}$ (Fig. S4, Supplement Sect. S2.5). The optimum was reached at $0.43 \mathrm{mg} \mathrm{mL}^{-1}$ whereas a decrease in the oxime formation can be observed over this concentration. Based on this result, the PFBHA concentration was set to $0.43 \mathrm{mg} \mathrm{mL}^{-1}$. Such a decrease has been reported in the literature examining acrolein, glyoxal and methyl glyoxal which is explained by a less effective extraction of the oxime due to an increasing amount of PFBHA in the organic phase (Saison et al., 2009). In a number of studies an optimisation of the PFBHA concentration cannot be found (Glaze et al., 1989; Hudson et al., 2007; Lelacheur et al., 1993; Spaulding and Charles, 2002; Sugaya et al., 2004) as only few studies exist examining this issue (EPA method 556, 1998; Kobayashi et al., 1980; Saison et al., 2009; Seaman et al., 2006; Serrano et al., 2013; Strass- nig et al., 2000; Ye et al., 2011). Nevertheless, $0.43 \mathrm{mg} \mathrm{mL}^{-1}$ found in the present study are in good agreement to a study by Serrano et al. (2013) which recommended $0.3 \mathrm{mg} \mathrm{mL}^{-1}$. Even if much lower PFBHA concentrations were found to be optimal a much higher PFBHA concentration was used to ensure a complete derivatisation. Despite these facts two studies exist which found much lower PFBHA concentration of 0.1 and $0.05 \mathrm{mg} \mathrm{mL}^{-1}$ as optimal (Kobayashi et al., 1980; Ye et al., 2011). They investigated only saturated carbonyl compounds which could be a reason for the lower PFBHA amount. Furthermore Strassnig et al. (2000) optimised the PFBHA amount concluding the best PFBHA amount is $0.8 \mathrm{mg} \mathrm{mL}^{-1}$ which is two times higher than the optimal PFBHA amount found in this study. It should be mentioned that the derivatisation was conducted in a microwave oven therefore the derivatisation occurred under other conditions than in this study. Furthermore for the derivatisation of the carbonyl compound with the EPA method 556 (1998) also a higher PFBHA amount of $0.75 \mathrm{mg} \mathrm{mL}^{-1}$ is used. This finding cannot be compared because the derivatisation was carried out at a temperature of $35^{\circ} \mathrm{C}$.

\section{5 $\mathrm{pH}$ value during derivatisation and extraction}

The $\mathrm{pH}$ value was varied between $\mathrm{pH}=1$ and 7 with hydrochloric acid and sodium hydroxide for the investigation of the influence of the $\mathrm{pH}$ value on the quantification of the carbonyl compounds. The $\mathrm{pH}$ value can be varied for two experimental steps, first the $\mathrm{pH}$ value of the derivatisation reaction (Fig. S5, Supplement Sect. S2.6) and second, the extraction of the oxime (Fig. S6, Supplement Sect. S2.6). No influence of the $\mathrm{pH}$ value on the derivatisation step was observed (Fig. S5). Based on this a $\mathrm{pH}$ value of 3 was chosen because this requires no further addition of hydrochloric acid or sodium hydroxide and second, it was found that at $\mathrm{pH}=3$ the standard deviation (SD, three repetitions) was lower. After the derivatisation with PFBHA the oxime is extracted with dichloromethane. This step was also found to be not $\mathrm{pH}$ dependent (Fig. S6). However, under highly acidic conditions a smaller fraction of PFBHA was found in the organic phase. The smaller fraction of PFBHA might be caused by a less pronounced phase transfer of PFBHA in the organic phase when the aqueous phase was acidified to $\mathrm{pH}=1(\mathrm{Yu}$ 

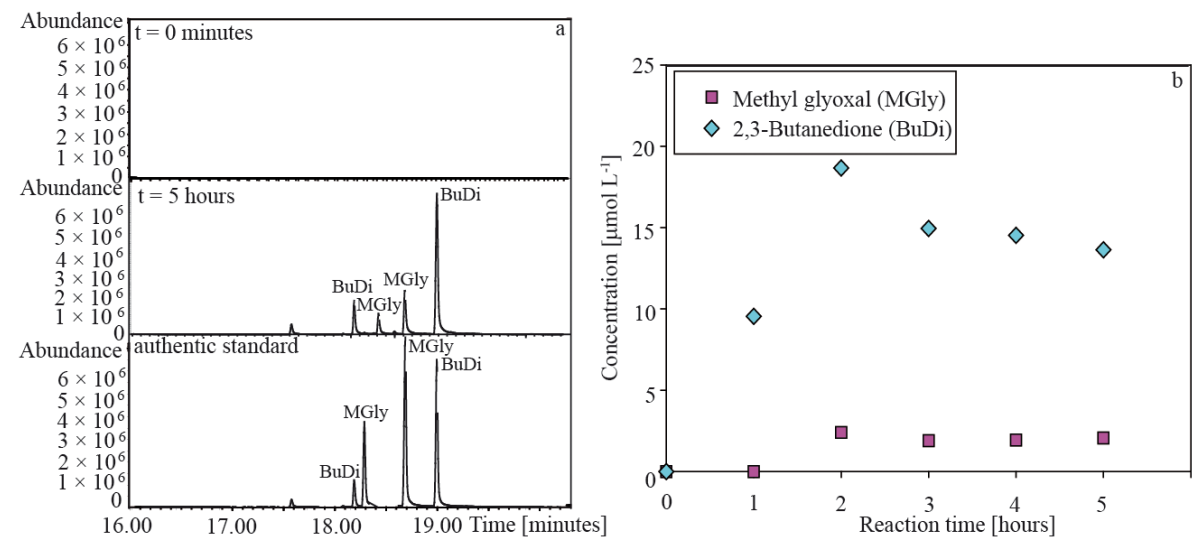

Figure 2. Time-resolved GC/MS chromatograms obtained from the oxidation of 3 -methylbutanone (starting time $\mathrm{t}=0 \mathrm{~h}$ and reaction time $\mathrm{t}=5 \mathrm{~h}$ ). For comparison the GC/MS chromatogram of the authentic standard compounds of the identified products 2,3-butanedione (BuDi) and methyl glyoxal (MGly) are shown (a). Using the obtained chromatograms, the concentration of the main products BuDi and MGly was calculated (b).

et al., 1995). Therefore the $\mathrm{pH}$ value for the extraction of the oxime was set to $\mathrm{pH}=1$ as it minimises the amount of PFBHA in the organic phase and thus in the chromatogram.

\subsection{Proof of principle}

The optimised method was evaluated to detect and quantify carbonyl compounds formed during the oxidation of 3-methylbutanone with $\mathrm{OH}$ radicals in the aqueous solution. Among numerous oxidation products methyl glyoxal and 2,3-butanedione (Fig. 2a) were positively identified and quantified with the developed method. Methyl glyoxal and 2,3-butanedione could not be detected at the beginning of the experiment (Fig. 2b). After 1 hour the peak areas of the carbonyl compounds start to increase as they are formed by the reaction. For both compounds two peaks were found corresponding to (E) and (Z) isomers of the oximes (Glaze et al., 1989). The reaction was stopped after $5 \mathrm{~h}$ and the products were quantified with authentic standard compounds. The determined concentrations were $2.1 \mu \mathrm{mol} \mathrm{L} \mathrm{L}^{-1}$ for methyl glyoxal and $13.6 \mu \mathrm{mol} \mathrm{L}^{-1}$ for 2,3-butanedione after $5 \mathrm{~h}$. This corresponds to a yield of $2 \%$ for methyl glyoxal and $14 \%$ for 2,3-butanedione.

\section{Summary}

The present study showed that dichloromethane gives a better recovery of the oximes compared to the commonly used hexane for the derivatisation of carbonyl compounds with PFBHA in aqueous solution. Furthermore, the extraction time was set to $30 \mathrm{~min}$ which corresponds to an increase by a factor of up to 60 compared to previously published methods (e.g. Glaze et al., 1989). Furthermore, the derivatisation time was increased by a factor of up to 12 (Glaze et al., 1989). The improvement enabled a much better detection limit be- tween 0.01 and $0.17 \mu \mathrm{mol} \mathrm{L} \mathrm{L}^{-1}$ for seven carbonyl compounds tested in this study. In addition the derivatisation time was set to $24 \mathrm{~h}$ to complete the derivatisation of carbonyl compounds bearing a keto group. To investigate the effect of the amount of derivatisation reagent, different PFBHA concentrations were added and the best result was found at a concentration of $0.43 \mathrm{mg} \mathrm{mL}^{-1}$.

The optimised method was applied to detect carbonyl compounds formed during the oxidation of 3methylbutanone in aqueous phase, namely methyl glyoxal and 2,3-butanedione. The results obtained from the analysis of laboratory-produced samples showed that the developed method is suitable for the detection and quantification of carbonyl compounds in aqueous samples, especially in low quantities.

\section{The Supplement related to this article is available online at doi:10.5194/amt-8-2409-2015-supplement.}

Acknowledgements. This study was supported by the Scholarship Programme of the German Federal Environmental Foundation (Deutsche Bundesstiftung Umwelt, DBU; grant number 20013/244).

Edited by: P. Herckes

\section{References}

Altshuller, A. P.: Measurements of the products of atmospheric photochemical-reactions in laboratory studies and in ambient airrelationships between ozone and other products, Atmos. Environ, 17, 2383-2427, 1983. 
Atkinson, R. and Aschmann, S. M.: Products of the gas-phase reactions of aromatic-hydrocarbons - Effect of $\mathrm{NO}_{2}$ concentration, Int. J. Chem. Kinet., 26, 929-944, 1994.

Calvert, J. G. and Madronich, S.: Theoretical-study of the initial products of the atmospheric oxidation of hydrocarbons, J. Geophys. Res.-Atmos., 92, 2211-2220, 1987.

Cancho, B., Ventura, F., and Galceran, M. T.: Determination of aldehydes in drinking water using pentafluorobenzylhydroxylamine derivatization and solid-phase microextraction, J. Chromatogr. A, 943, 1-13, 2002.

Carlier, P., Hannachi, H., and Mouvier, G.: The chemistry of carbonyl-compounds in the atmosphere - A review, Atmos. Environ, 20, 2079-2099, 1986.

Cullere, L., Cacho, J., and Ferreira, V.: Analysis for wine $\mathrm{C}_{5^{-}}$ $\mathrm{C}_{8}$ aldehydes through the determination of their O- $(2,3,4,5,6-$ pentafluorobenzyl)oximes formed directly in the solid phase extraction cartridge, Anal. Chim. Acta, 524, 201-206, 2004.

EPA method 556: Determination of carbonyl compounds in drinking water by pentafluorobenzylhydroxylamine derivatisation and capillary gas chromatography with electron capture detection, National exposure research laboratory office of research and development US Environmental Protection Agency Cincinnati, Ohio, 45268, 1998.

Ervens, B. and Volkamer, R.: Glyoxal processing by aerosol multiphase chemistry: towards a kinetic modeling framework of secondary organic aerosol formation in aqueous particles, Atmos. Chem. Phys., 10, 8219-8244, doi:10.5194/acp-10-8219-2010, 2010.

Fu, T. M., Jacob, D. J., Wittrock, F., Burrows, J. P., Vrekoussis, M., and Henze, D. K.: Global budgets of atmospheric glyoxal and methylglyoxal, and implications for formation of secondary organic aerosols, J. Geophys. Res.-Atmos., 113, doi:10.1029/2007JD009505, 2008.

Glaze, W. H., Koga, M., and Cancilla, D.: Ozonation by-products .2. Improvement of an aqueous-phase derivatization method for the detection of formaldehyde and other carbonyl-compounds formed by the ozonation of drinking-water, Environ. Sci. Technol., 23, 838-847, 1989.

Grosjean, D.: Formaldehyde and other carbonyls in Los-Angeles ambient air, Environ. Sci. Technol., 16, 254-262, 1982.

Hallquist, M., Wenger, J. C., Baltensperger, U., Rudich, Y., Simpson, D., Claeys, M., Dommen, J., Donahue, N. M., George, C., Goldstein, A. H., Hamilton, J. F., Herrmann, H., Hoffmann, T., Iinuma, Y., Jang, M., Jenkin, M. E., Jimenez, J. L., Kiendler-Scharr, A., Maenhaut, W., McFiggans, G., Mentel, Th. F., Monod, A., Prévôt, A. S. H., Seinfeld, J. H., Surratt, J. D., Szmigielski, R., and Wildt, J.: The formation, properties and impact of secondary organic aerosol: current and emerging issues, Atmos. Chem. Phys., 9, 5155-5236, doi:10.5194/acp-9-51552009, 2009.

Herrmann, H., Ervens, B., Nowacki, P., Wolke, R., and Zellner, R.: A chemical aqueous phase radical mechanism for tropospheric chemistry, Chemosphere, 38, 1223-1232, 1999.

Hudson, E. D., Okuda, K., and Ariya, P. A.: Determination of acetone in seawater using derivatization solid-phase microextraction, Anal. Bioanal. Chem., 388, 1275-1282, 2007.

Jang, M. S. and Kamens, R. M.: Characterization of secondary aerosol from the photooxidation of toluene in the presence of
$\mathrm{NO}_{x}$ and 1-propene, Environ. Sci. Technol., 35, 3626-3639, 2001.

Kobayashi, K., Tanaka, M., and Kawai, S.: Gas-chromatographic determination of low-molecular-weight carbonyl-compounds in aqueous-solution as their O-(2,3,4,5,6-pentafluorobenzyl) oximes, J. Chromatogr., 187, 413-417, 1980.

Kroll, J. H., Ng, N. L., Murphy, S. M., Flagan, R. C., and Seinfeld, J. H.: Secondary organic aerosol formation from isoprene photooxidation, Environ. Sci. Technol., 40, 1869-1877, 2006.

Leikauf, G. D.: Hazardous air pollutants and asthma, Environ. Health Perspect., 110, 505-526, 2002.

Lelacheur, R. M., Sonnenberg, L. B., Singer, P. C., Christman, R. F., and Charles, M. J.: Identification of carbonyl-compounds in environmental-samples, Environ. Sci. Technol., 27, 2745-2753, 1993.

Loeffler, K. W., Koehler, C. A., Paul, N. M., and De Haan, D. O.: Oligomer formation in evaporating aqueous glyoxal and methyl glyoxal solutions, Environ. Sci. Technol., 40, 6318-6323, 2006.

Lowe, D. C., Schmidt, U., and Ehhalt, D. H.: A new technique for measuring tropospheric formaldehyde $\mathrm{CH}_{2} \mathrm{O}$, Geophys. Res. Lett., 7, 825-828, 1980.

Nawrocki, J., Kalkowska, I., and Dabrowska, A.: Optimization of solid-phase extraction method for analysis of low-ppb amounts of aldehydes-ozonation by-products, J. Chromatogr. A, 749, 157-163, 1996.

Pang, X. B., Lewis, A. C., and Rodenas-Garcia, M.: Microfluidic lab-on-a-chip derivatization for gaseous carbonyl analysis, J. Chromatogr. A, 1296, 93-103, 2013.

Platt, U., Perner, D., and Patz, H. W.: Simultaneous measurement of atmospheric $\mathrm{CH}_{2} \mathrm{O}, \mathrm{O}_{3}$, and $\mathrm{NO}_{2}$ by differential opticalabsorption, J. Geophys. Res.-Oceans, 84, 6329-6335, 1979.

Ravishankara, A. R.: Heterogeneous and multiphase chemistry in the troposphere, Science, 276, 1058-1065, 1997.

Saison, D., De Schutter, D. P., Delvaux, F., and Delvaux, F. R.: Determination of carbonyl compounds in beer by derivatisation and headspace solid-phase microextraction in combination with gas chromatography and mass spectrometry, J. Chromatogr. A, 1216, 5061-5068, 2009.

Schaefer, T., Schindelka, J., Hoffmann, D., and Herrmann, H.: Laboratory kinetic and mechanistic studies on the $\mathrm{OH}$-initiated oxidation of acetone in aqueous solution, J. Phys. Chem. A, 116, 6317-6326, 2012.

Schütze, M. and Herrmann, H.: Uptake of acetone, 2-butanone, 2,3butanedione and 2-oxopropanal on a water surface, Phys. Chem. Chem. Phys., 6, 965-971, 2004.

Seaman, V. Y., Charles, M. J., and Cahill, T. M.: A sensitive method for the quantification of acrolein and other volatile carbonyls in ambient air, Anal. Chem., 78, 2405-2412, 2006.

Seaman, V. Y., Bennett, D. H., and Cahill, T. M.: Indoor acrolein emission and decay rates resulting from domestic cooking events, Atmos. Environ, 43, 6199-6204, 2009.

Serrano, M., Silva, M., and Gallego, M.: Development of an environment-friendly microextraction method for the determination of aliphatic and aromatic aldehydes in water, Anal. Chim. Acta, 784, 77-84, 2013.

Sierau, B., Stratmann, F., Pelzing, M., Neususs, C., Hofmann, D., and Wilck, M.: A condensation-growth and impaction method for rapid off-line chemical-characterization of organic submi- 
crometer atmospheric aerosol particles, J. Aerosol Sci., 34, 225242, 2003.

Sorooshian, A., Brechtel, F. J., Ma, Y. L., Weber, R. J., Corless, A., Flagan, R. C., and Seinfeld, J. H.: Modeling and characterization of a particle-into-liquid sampler (PILS), Aerosol Sci. Tech., 40, 396-409, 2006.

Spaulding, R. S. and Charles, M. J.: Comparison of methods for extraction, storage, and silylation of pentafluorobenzyl derivatives of carbonyl compounds and multi-functional carbonyl compounds, Anal. Bioanal. Chem., 372, 808-816, 2002.

Strassnig, S., Wenzl, T., and Lankmayr, E. P.: Microwave-assisted derivatization of volatile carbonyl compounds with O-(2,3,4,5,6pentafluorobenzyl)hydroxylamine, J. Chromatogr. A, 891, 267273, 2000.

Sugaya, N., Sakurai, K., Nakagawa, T., Onda, N., Onodera, S., Morita, M., and Tezuka, M.: Development of a headspace GC/MS analysis for carbonyl compounds (aldehydes and ketones) in household products after derivatization with o(2,3,4,5,6-pentafluorobenzyl)-hydroxylamine, Anal. Sci., 20, 865-870, 2004.
Takeuchi, A., Takigawa, T., Abe, M., Kawai, T., Endo, Y., Yasugi, T., Endo, G., and Ogino, K.: Determination of formaldehyde in urine by headspace gas chromatography, B. Environ. Contam. Tox., 79, 1-4, 2007.

ten Brink, H., Otjes, R., Jongejan, P., and Kos, G.: Monitoring of the ratio of nitrate to sulphate in size-segregated submicron aerosol in the Netherlands, Atmos. Res., 92, 270-276, 2009.

Tuazon, E. C., Graham, R. A., Winer, A. M., Easton, R. R., Pitts, J. N., and Hanst, P. L.: Kilometer pathlength Fourier-transform infrared system for study of trace pollutants in ambient and synthetic atmospheres, Atmos. Environ, 12, 865-875, 1978.

Ye, Q., Zheng, D., Liu, L., and Hong, L.: Rapid analysis of aldehydes by simultaneous microextraction and derivatization followed by GC-MS, J. Sep. Sci., 34, 1607-1612, 2011.

Yu, J. Z., Jeffries, H. E., and Lelacheur, R. M.: Identifying airborne carbonyl-compounds in isoprene atmospheric photooxidation products by their PFBHA oximes using gas-chromatography ion-trap mass-spectrometry, Environ. Sci. Technol., 29, 1923 1932, 1995. 